\section{ORAL AND MAXILLOFACIAL SURGERY}

\section{Surgical management of cutaneous squamous cell carcinoma of the head and neck}

Baker NJ, Webb AAC et al. Br J Oral Maxillofac Surg 2001; 39: 87-90

A cure rate of 97\% was reported for 227 squamous cell carcinoma (SCC) lesions in 183 patients (mean age 78 yrs; 73\% male) with a minimum 2-year follow-up.

In this study from 2 Sussex hospitals, $26 \%$ of SCCs were on the ear, $20 \%$ on the scalp, $14 \%$ on the cheek, and 10\% on the forehead with most of the remainder in the lower lip, neck, temple and nose. In 9\% of patients, more than 1 primary presented, and 14\% later developed a further primary.

All cases were treated with surgical excision followed by primary closure in half and grafting in the remainder. Incomplete excision was reported for 16 cases, 6 of them on the scalp. In 11 of these which were observed subsequently, 3 SCCs recurred locally and were treated with further excision or radiotherapy; 5 others were treated similarly with no delay. Another 6 recurred following full excision; 5 were treated further and 2 of these patients died of metastatic disease.

ORAL SURGERY; DEVELOPMENTAL PATHOLOGY

Third molar outcomes from age 18-26: findings from a population-based New Zealand longitudinal study

Kruger E, Thomson WM et al. Oral Surg 2001; 92: 150-155

Around 70\% of teeth with impactions other than horizontal at 18 yrs erupted fully by age 26 .

In 821 subjects who were part of a cohort of 1037 followed from birth, 2857 third molars were assessed clinically and radiographically at $18 \mathrm{yrs}$, and 93\% of these were followed up clinically at 26 yrs. The 45 subjects not followed up had higher DMF and OHI-S at age 18 .

At 18 yrs, 15\% of maxillary teeth were fully erupted; 26\% were not impacted, 29\% were impacted mesially, 18\% vertically, 12\% distally, none horizontally. Respective mandibular scores were 20\%, 3\%, 63\%, 12\%, 1\%, 1\%.

At age 26, about 30\% of teeth had been extracted in both jaws; $40 \%$ of maxillary and $20 \%$ of mandibular mesially impacted teeth had fully erupted, and another $1 / 3$ of each had been extracted; for distal impaction, respective figures were 20\%, 32\%, 22\% and 32\%.
Over $1 / 5$ of non-impacted teeth had also been extracted, showing that other factors affect this clinical decision.

\section{DEVELOPMENTAL PATHOLOGY; ORAL MEDICINE}

Oligodontia is associated with extra-oral ectodermal symptoms and low whole salivary flow rates

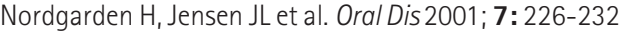

The majority of a group of oligodontic patients had other signs which could be linked to their condition.

This Norwegian study compared 68 oligodontic persons (39 with ectodermal dysplasia: ED; 29 without: non-ED) and 39 healthy controls matched to ED. Median age was 12 yrs. The ED group had disturbances in hair, nails and/or sweat production, and more missing teeth than the non-ED group (median 13 v.10). Incisors, canines and molars were more often absent in ED than non-ED, but not premolars.

In the ED group, dry skin, asthma and eczema were more prevalent than in controls (respective $P: 0.002,0.09,0.08$ ); the non-ED group had intermediate levels of dry skin and asthma, but the same prevalence of eczema as ED. Salivary flow was lower in ED than controls, and the whole oligodontic group showed an inverse correlation between the number of missing teeth and salivary flow rate, which may relate to reduced volume of salivary glands.

\section{DENTAL A \& E; HEALTH INSURANCE}

\section{Travel insurance claims made by travellers} from Australia for dental conditions

\section{Leggat PA, Leggat FW et al. Int Dent J 2001; 51: 267-272}

During 1 year, $8 \%$ of all claims to a large travel insurance company were for dental conditions, and $2 / 3$ of these were accepted.

In 1998-9, a major Australian company had 1289 travel insurance claims, of which 104 were for dental conditions. More than half of these were in claimants aged $60+$ and $3 / 5$ were from females. In no cases were journeys curtailed, or claimants evacuated. The median time at which treatment was sought was 21 days into travel.

Conservative treatment was the subject of the claim in 30\%, prosthodontics in 26\%, endodontics in 18\% and periodontics in $8 \%$. The least likely claims to be accepted were prosthodontic. The median claim paid was £89 for males and £68 for females. The most expensive claims involved prosthodontics, oral surgery or endodontics. 